\title{
Recyclable Magnetic Superhydrophobic Straw Soot Sponge for Highly Efficient Oil/water Separation
}

\author{
Farshad Beshkar, Hossein Khojasteh, Masoud Salavati-Niasari* \\ Institute of Nano Science and Nano Technology, University of Kashan, Kashan, P. O. Box 87317-51167, Islamic \\ Republic of Iran \\ *Corresponding author. Tel. +98315 5912383; Fax +983155913201 \\ E-mail address: salavati@kashanu.ac.ir
}

\begin{abstract}
A simple and low-cost route to fabricate durable superhydrophobic magnetic polyurethane sponge was obtained by immersing a polyurethane sponge in a colloidal suspension of straw soot and magnetic nanoparticles. The as prepared sponge was used for separation of oil/water mixture. XRD, FT-IR, VSM, SEM and contact angle measurement analysis were used for characterization the materials. The effects of different stabilizer or surfactants (cetyltrimethylammonium bromide (CTAB), sodium dodecylsulfate (SDS) and polyethylene glycol 6000 (PEG 6000)) on the morphology and geometrical structure of magnetic nanoparticles were investigated. For increasing the hydrophobic property of the surface, the sponge was further modified using PDMS. Results indicated that this matter can promote interfacial interactions between the sponge surface and oil. The prepared sponge showed excellent superhydrophobicity with water contact angle as high as $154^{\circ}$. Experiments showed that the amount of the absorbed oil was about 30 times of sponges own weight, it has our 30 times recyclability and the advantage of magnetic separation.
\end{abstract}


KEYWORDS: Straw soot; Oil/water separation; Superhydrophobic; Magnetic nanoparticles; Colloidal suspention.

\section{Introduction}

Oil drilling has been around for more than a century. Because of the numerous developments in the technology, application of oil and its derivatives in different industries has been also developed. The oil and petroleum industry includes the global processes of exploration, drilling, extraction, refining, transporting and marketing different petroleum products. Recently, sea water pollution resulting from oil leakage and industrial waste organic pollutants has emerged as a critical problem imposing threat to the human and animal health $[1,2]$. For example, the Gulf of Mexico oil spill in 2010 is one of the most famous and serious pollution incidents in recent decades in the world [3].

To address this challenge, many methods are currently employed to solve oil spill problems. Some of these methods include coagulation/flocculation, in situ burning, skimming, centrifugation and gravity separation. Among these procedures, carbon-based absorbents demonstrate superior efficiency in the removal of oils and other organic pollutants $[4,5]$. Meanwhile, gathering and recovery of oil spills using a sponge-like absorbent materials are promising methods and have got great attention due to their low cost and high cleanup efficiency [6]. To determine a material with ideal properties for efficient adsorption of oil, it should have a high specific surface area, high hydrophobic nature, reusability and excellent chemical stability [6].

Polymer foams have been employed as a good candidate for oil absorbents due to their large surface area, flexibility and controllable hydrophobic property [7, 8]. Among the various sponges, polyurethane sponge is a kind of porous, hydrophilic, light weight, good elasticity, and very low-cost for large-scale production. These properties endow polyurethane (PU) sponge promising applications in the different fields such as sorption, filtration, and separation [9]. But this sponge cannot be used as an oil absorbent by itself. Because a desirable oil absorbent 
should have the following functions. Firstly, the sponge should be modified in a way that has the selective absorption capacity and can absorb various oils and organic pollutants. Also, the introduced sponge should have excellent hydrophobicity and oleophilicity to repulse water. The other needed property is reusability and absorption capacity, in a way that the material should still remain and reserve high absorption capacity and water contact angle after repetitive cycles [10-12].

One of the simple ways to modify the sponges to achieve excellent hydrophobic property is the surface functionalization with carbon materials. Carbon-based materials are a good candidate with high absorption capacity, good selectivity, and environment-friendly properties of oil absorption [13, 14]. In this context, various kinds of carbon-based materials have been developed to remove petroleum products and other organic pollutants in water. For example activated carbon, expanded graphite, carbon fiber, carbon nanotubes (CNTs) and graphene have been used as oil/water separation successfully [6, 15-19]. Among the variety of carbon-based materials, carbon soot is more economical. Soot is a product of impure carbon particles resulting from the pyrolysis processes involving carbon-containing fuel and incomplete combustion of organic materials [20]. Carbon soot is an inexpensive, non-toxic and easily obtained material that is used in current chemical research and can be used for a variety of chemistry demonstrations [21]. The particle size of soot grains is often small in the nanometer range, classifying them as nanoparticles and make roughness at the nanoscale level on the substrates [22, 23]. Most of the carbon soot is nonpolar and insoluble in polar solvents such as water. These properties for carbon soot, lead generating an excellent water-resistant or superhydrophobic surface. On the other hand, we can use of the magnetic property to facilitate the separation. For example, in the catalyst region, magnetic separation is an attractive way to retrieve catalysts. Because it prevents loss of the catalyst, improve the reusability and reduce costs [24].

Here, we describe a simple and low-cost way to make a durable and modified magnetic superhydrophobic polyurethane sponge using soot resulted of combustion of natural plant straw for removing oils from water surface 
under. Deposition of a straw soot layer was performed by immersing the cleaned sponge in a colloidal suspension of the amorphous carbon nanoparticles that turns the sponge black. During the preparation process, soot particles were assembled on the surface of polyurethane skeletons. All of the reactions were carried out in moderate temperature, environmental atmosphere, and pressure. The as modified sponge has a high absorption capacity for a broad variety of oils and organic solvents from oil-water mixtures. In comparison with previous works, we used a simpler and cheaper route to prepare magnetic hydrophobic sponge. The as prepared sponge had good interface interaction with oil making it as grateful oil absorbent. Moreover, the experiments approved that the sponge can remain high oil absorption capacity after several absorption/desorption cycles. The observations demonstrate the good reusability of sponge.

\section{Experimental Section}

A piece of commercial polyurethane foam was cleaned and dried in an oven at $70{ }^{\circ} \mathrm{C}$ for 30 min. The grown straw soot on the glass slide was collected by shaving soot from the glass using a spatula (Fig.S1, ESI). The superhydrophobic foam was prepared by a dip-coating method in a colloidal suspension of soot in ethanolic medium (as described in ESI) [25]. The magnetic properties of the samples were detected at room temperature using a vibrating sample magnetometer (VSM, Meghnatis Kavir Kashan Co., Kashan, Iran). After that the cleaned polyurethane sponge was dipped into the straw soot dispersion and dried, the hydrophobic sponge was obtained that can float on the water surface versus non-modified sponge (Fig.S2, ESI). The magnetic NPs were synthesized using a simple microwave assisted method using hydrazine as the catalyst in the presence of ethylene glycol (see ESI). The effects of the absence or presence of different stabilizer or surfactants (CTAB, SDS and PEG6000) with a specific molar ratio $\left(\mathrm{Fe}(\mathrm{acac})_{3}:\right.$ Surfactant $\left.=1: 2\right)$ before adding the hydrazine on final produced structures were investigated. The magnetic hydrophobic sponge was obtained by immersing the hydrophobic sponge in $20 \mathrm{ml}$ of absolute ethanol containing magnetic nanoparticles.

\section{Results and discussion}


The as prepared $\mathrm{Fe}_{3} \mathrm{O}_{4}$, straw soot and final modified foam are characterized by X-Ray Diffraction Analysis (XRD), Fourier Transform- Infrared Spectroscopy (FT-IR), Scanning Electron Microscopy (SEM), contact angle measurement \& VSM analysis.

\subsection{XRD characterization}

The structure of the $\mathrm{Fe}_{3} \mathrm{O}_{4}$ magnetic nanoparticles and collected straw soot was characterized using XRD analysis. The obtained result is depicted Fig. 1. It can be seen that, the magnetic nanopowder is a crystalline material (Fig.1a). For the $\mathrm{Fe}_{3} \mathrm{O}_{4}$ nanoparticles, six diffraction peaks were observed in $2 \Theta=30.51,35.89,43.58$, 54.01, 57.61 and 63.24 that corresponds to crystalline $\mathrm{Fe}_{3} \mathrm{O}_{4}$ magnetic nanostructures (JCPDS card no. 75-0449). The XRD pattern of straw soot in Fig.2b shows that there is a broad and low intensity Bragg diffraction peak at near $2 \theta=24^{\circ}$ which is attributed to (002) orientation. In the previous investigations, it has been reported that the XRD peak at near $2 \theta=24^{\circ}$ is an indication of the presence of large amounts of amorphous material such as amorphous carbon nanoparticles in association with hexagonal graphite lattice [26]. The low intensity with a broad peak proves that the soot particles are in nanoscale.

\subsection{FT-IR analysis}

FT-IR spectrum For both $\mathrm{Fe}_{3} \mathrm{O}_{4}$ magnetic nanoparticles and soot samples, show the broadband at $3450 \mathrm{~cm}^{-1}$ assigned to the stretching vibrations of the remained surface hydroxyl $(-\mathrm{OH})$ groups and another band around $1244 \mathrm{~cm}^{-1}$ that is related to the bending vibration of the $\mathrm{H}-\mathrm{O}-\mathrm{H}$ bonds (Fig.S3, ESI). These peaks have higher intensity for magnetic sample due to the large amount of hydroxyl functional groups on its surface in comparison with soot sample. It assumes the intensities and sharpness of the bands have direct relation with the amount of functional groups in the sample. Therefore, it can be concluded that because of presence large amount of polar functional groups, the $\mathrm{Fe}_{3} \mathrm{O}_{4}$ sample has more hydrophilicity property versus straw soot. 


\subsection{Morphology of straw soot and magnetic $\mathrm{Fe}_{3} \mathrm{O}_{4}$ nanopowders}

A significant feature in the FT-IR spectrum of the $\mathrm{Fe}_{3} \mathrm{O}_{4}$ sample was the appearance of stretching vibration of $\mathrm{Fe}-\mathrm{O}$ at $582 \mathrm{~cm}^{-1}$. Also, the absorption band at approximately $1620 \mathrm{~cm}^{-1}$ relating to the vibrations of hydroxyl groups of adsorbed water or water of $\mathrm{KBr}$ used for spectroscopy. The band observed at about $1030 \mathrm{~cm}^{-1}$ was assigned to the $\mathrm{CO}$ stretching of different carbonic functional groups on the sample surfaces [27]. In the $\mathrm{Fe}_{3} \mathrm{O}_{4}$ sample there is also this band that can be related to some residual acetylacetonate ligands in the structure. Both synthesized $\mathrm{Fe}_{3} \mathrm{O}_{4}$ and straw soot have absorption peaks at approximately $2920 \mathrm{~cm}^{-1}$ and $2850 \mathrm{~cm}^{-1}$ corresponding to the symmetric and anti-symmetric stretching vibration frequency of $\mathrm{CH}_{2}$ groups. Once again, these bands probably are related to some residual acetylacetonate ligands in the magnetic structure. The SEM micrographs of magnetic nanoparticles are given in Fig.2. Here, the effects of absence (F0 sample) or presence of different stabilizer or surfactants $(\mathrm{F} 1=\mathrm{CTAB}, \mathrm{F} 2=\mathrm{PEG} 6000$ and F3 $=$ SDS $)$ on the morphology and geometrical structure of final produced structures were investigated. The SEM images for F0 reveal that, the particles are almost uniform in size with spherical geometry, relatively dense and with the average size of nanoparticles is about $80 \mathrm{~nm}$ (Fig.2a). SEM results indicate that smaller (average size of $62 \mathrm{~nm}$ ) and more individual particles were obtained using CTAB as a cationic surfactant as shown in Fig. 2b (sample F1). As shown in Fig.2c, when PEG 6000 was used as capping agent (F2 sample), coalesced structures of nanoparticles are made. We can propose, because PEG 6000 is a macromolecule with high molecular weight and acts as neutral surfactant, so its interaction with iron ions is not impressive and strong and production of aggregated structures can be expected. In the following reaction, for the sample with SDS as an anionic surfactant (F3 sample), the images show that uniform nanoparticles with sphere-like shape and with average particle size of $50 \mathrm{~nm}$ are prepared (Fig. 2d). It seems that these surfactants are adsorbed preferentially on the primary nucleus surface to inhibit the aggregation and density by the different steric hindrance mechanisms. The obtained results from SEM images depict that the type of surfactant has an important effect on the size of nanostructures in microwave route and for reaching the smaller and more uniform $\mathrm{Fe}_{3} \mathrm{O}_{4}$ nanoparticles, SDS is a suitable candidate. SEM image for straw soon product revealed that the airborne 
thermolytic particles are extremely small and occur individually (Fig.S4, ESI). Some particles are seen to form aggregates on the glass collector plate. The obtained particles are a complex mixture of elemental carbon and a variety of hydrocarbons; soot particles are extremely small with a majority of the particles about $62 \mathrm{~nm}$ in diameter and spherical shape. A calculation of the amount of the soot loading was determined by weighing the initial sponge and soot-coated sponge immediately after being taken out of the oven. Results showed that the amount of powder loading is 5\%. Typical TEM micrographs of the soot prepared from plant source and magnetic nanoparticles are shown in Fig.3. As can be seen, the carbon soot particles are rather uniform in size with a mean size of $60 \mathrm{~nm}$ in diameter (Fig.3a and Fig.3b). TEM analysis of $\mathrm{Fe}_{3} \mathrm{O}_{4}$ indicated that $\mathrm{Fe}_{3} \mathrm{O}_{4}$ nanoparticles were approximately spherical in nature with sizes ranging from 20 to $30 \mathrm{~nm}$, with an average of $25 \mathrm{~nm}$ (Fig.3b).

\subsection{Investigation of Magnetic characteristics}

VSM results indicate that the magnetic hysteresis loops are S-like curves, the magnetic remanence of the sample was nearly zero suggests that samples exhibit a superparamagnetic behavior (Fig.S5, ESI). The specific saturation magnetization (Ms) is about $40 \mathrm{emu} / \mathrm{g}$ for $\mathrm{Fe}_{3} \mathrm{O}_{4}$ MNPs. Due to this magnetic property the magnetic oleophilic foam could absorb by an external magnet at the end of the separation process. It is commonly confirmed that the unusual wetting properties of superhydrophobic surfaces are depended on both their chemical composition and geometric surface microstructure [28]. In addition, the characteristic of wettability of a surface can be wellcontrolled through the combination of surface roughness and the different chemical modification.

\subsection{Foam superhydrophobicity}

It is commonly confirmed that the unusual wetting properties of superhydrophobic surfaces are depended on both their chemical composition and geometric surface microstructure [28]. In addition, the characteristic of wettability of a surface can be well-controlled through the combination of surface roughness and the different chemical modification. It is expected that as-prepared sponge with special nanostructures may result in a particular 
wettability. Considering the nanoscale binary of the magnetic and straw soot particles covered PU sponge, the wetting properties of the foam were evaluated using contact angle (CA) measurements. Fig.4 shows the captured micrographs of a water droplet on the surface of the foam. As can be seen in Fig.4a, for the straw soot coated foam, the corresponding CA is determined to be $142^{\circ}$, indicative of the good surface hydrophobicity.

For increasing the contact angle of a water droplet, the surface of as prepared sponge was further modified as fallow; a hydrophobic sponge was also modified with stearic acid (SA). For that, the foam was immersed in $10 \mathrm{ml}$ of $0.05 \mathrm{M} \mathrm{SA}$ absolute ethanolic solution for 2 hours at $70^{\circ} \mathrm{C}$. Finally the modified substrate was dried at $70^{\circ} \mathrm{C}$ for 2 hours and stored at room temperature. The result of CA measurement is depicted in Fig.4c. As seen, the combination of the low surface energy SA and surface roughness (arising from the straw soot, foam pores and magnetic nanoparticles) leads to obtain a better hydrophobic surface with the static water contact angle of the approximately $143.5^{\circ}$. In other reaction, the surface of the sponge was modified with polydimethylsiloxane (PDMS). The intended substrate was putted in $10 \mathrm{ml}$ solution of 3\% solution (v/v) of PDMS in toluene for 2 hours at $70^{\circ} \mathrm{C}$. Finally, the foil was dried at $70^{\circ} \mathrm{C}$ for 2 hours and stored at room temperature and then its wettability has been investigated. Results for CA measurement confirmed that as modified substrate showed excellent superhydrophobicity with water contact angle as high as $154^{\circ}$ (Fig.4b). For this sample, the water droplets can roll off the surface very quickly when the substrate is slightly crooked. Thus, this sample was named as modified foam sample (MFS). Moreover, according to previous studies, it should be noted that usually the rough surfaces without modification have not superhydrophobic property and this suggests that only a suitable micro- nanoscale binary surface structure is not enough to achieve a superhydrophobic surface [28].

To further investigate the hydrophobic stability and performance of the MFS in the more complex environment, three kinds of the solutions such as acidic solution (prepared using $\mathrm{HCl}, \mathrm{pH}=2$ ), distilled water $(\mathrm{pH}=7)$ and basic solution (prepared using $\mathrm{NaOH}, \mathrm{pH}=14$ ) were introduced, respectively. Results indicate that the best contact angle 
can be achieved in the neutral solution. But compared with the MFS, the hydrophobicity of the sponge in contrast with the acidic solution was better than in the basic solution (Fig.5).

\subsection{Oil absorption performance}

The oil-water separation experiments were performed using the as-prepared optimized MFS to absorbing of waste oil (from Sepahan oil company, Isfahan, Iran). The schematic of experimental protocol for preparation and operation superhydrophobic/superoleophilic magnetic straw soot sponge is shown in Fig.6. Results indicate that the MFS is taken by a magnet bar and absorbs waste oil completely from the oil-water mixture just within 10 seconds. In the following, the sponge can be easily removed by an external magnet bar due to its magnetic properties (Fig.7). This method undoubtedly provides a facile and energy-saving procedure to collect oil from oilpolluted area. At the end of absorption process, the absorbed oils can be readily removed from the MFS through a simple mechanical extrusion method due to its excellent mechanical flexibility. Evaluation of the mass based absorption capacity showed that the amount of the absorbed oil was about 30 times of sponges own weight. The absorption capacity depends on density, viscosity and surface tension of the absorbed liquids [29].

The recyclability is an important issue regarding the practical and in large scale application of magnetic straw soot foam. The experiments demonstrated that the sponge can absorb the oil efficiently our 30 cyclic applications without significant change in the absorption. This property makes it possible to recycle both the sponge and absorbed liquids and endow the material to be an ideal candidate to separate oil pollutants from water. A wide range of oil/water separation materials has been investigated and in the previous literatures. Here, in the end, a comprehensive understanding and comparison of these reports has been discussed to evaluate their advantages and disadvantages. For a better comparison, some typical oil/water separation materials are listed in Table 1 depending on the as-introduced substrates in the former sections. As can be seen, our hydrophobic sponge has been obtained via a very simple preparation process, has the advantage of using of green and natural soot source and very cheap and inexpensive cost, and desirable adsorbent properties that makes that suitable for large scale production. 


\section{Conclusion}

In summary, magnetic hydrophobic sponge consisting of straw soot and $\mathrm{Fe}_{3} \mathrm{O}_{4}$ nanoparticles was fabricated by a facile immersion method. Due to using of a natural soot source this process is very cost effective and can perform in a short time. The effects of the absence or presence of different stabilizer or surfactants (CTAB, PEG6000 and SDS) on the morphology and geometrical structure of $\mathrm{Fe}_{3} \mathrm{O}_{4}$ nanoparticles structures were investigated. The obtained results from SEM images depict that the type of surfactant has an important effect on the size of nanostructures in microwave route and for reaching the smaller and more uniform $\mathrm{Fe}_{3} \mathrm{O}_{4}$ nanoparticles, SDS is a suitable candidate. The prepared materials were characterized by XRD, FT-IR, SEM, CA measurement and VSM analysis. Results indicate that straw soot anchored on the glass slide as spherical particles in nanometer scale. Moreover, the sponge exhibits significant magnetic properties and gave the outstanding separation performance with high absorption capacity using an external magnetic field. Finally, in the synthesis process, results indicated that modification of sponge with PDMS increases the contact angle of water droplet up to $154^{\circ}$. This superhydrophobic sample had good hydrophobic stability even in acidic condition and it can absorb waste oil completely from the oil-water mixture just within 10 seconds. Our developed method offers the benefits of easy preparation using natural soot source, better performance, oil absorption in a very short time, and magnetic separation in comparison with previous works [25, 30-34]. So we can introduce this product as a promising candidate for removal of oil contaminants from water surface. Later in the work, other sources of carbon soot can be used to generate hydrophobic property in the future works.

\section{Acknowledgements}

Authors are grateful to the council of Iran National Science Foundation (INSF) and University of Kashan for supporting this work by Grant No (159271/5519). 


\section{Figure captions}

Fig.1. Wide-angle XRD patterns of magnetic nanoparticles (a) and as prepared straw soot (b).

Fig.2. The SEM images a) F0 sample, b) F1 sample, c) F2 sample and F3 sample.

Fig. 3. TEM images for as prepared straw soot (a and b) and $\mathrm{Fe}_{3} \mathrm{O}_{4}$ (c).

Fig.4. CA values for PU sponge without further modification (a), modified by PDMS (b) and modified by SA (C).

Fig.5. The shapes of a water droplet with different $\mathrm{pH}$ values and the corresponding CA values.

Fig.6. Schematic illustration of preparation modified PU sponge and oil separation process.

Fig.7. Waste oil removal from water surface with MFS

Table captions

Table 1. A summary and comparisons of typical examples for various kinds of oil/water separation materials. 


\section{REFERENCES}

[1] H. Bi, X. Xie, K. Yin, Y. Zhou, S. Wan, L. He, F. Xu, F. Banhart, L. Sun, R.S. Ruoff, Spongy Graphene as a Highly Efficient and Recyclable Sorbent for Oils and Organic Solvents, Advanced Functional Materials 22(21) (2012) 4421-4425.

[2] H.-P. Cong, X.-C. Ren, P. Wang, S.-H. Yu, Macroscopic Multifunctional Graphene-Based Hydrogels and Aerogels by a Metal Ion Induced Self-Assembly Process, ACS Nano 6(3) (2012) 2693-2703.

[3] F. Zhao, L. Liu, F. Ma, L. Liu, Candle soot coated nickel foam for facile water and oil mixture separation, RSC Advances 4(14) (2014) 7132-7135.

[4] M. Toyoda, M. Inagaki, Heavy oil sorption using exfoliated graphite: New application of exfoliated graphite to protect heavy oil pollution, Carbon 38(2) (2000) 199-210.

[5] X. Gui, Z. Zeng, Z. Lin, Q. Gan, R. Xiang, Y. Zhu, A. Cao, Z. Tang, Magnetic and Highly Recyclable Macroporous Carbon Nanotubes for Spilled Oil Sorption and Separation, ACS Applied Materials \& Interfaces 5(12) (2013) 5845-5850.

[6] S. Yang, L. Chen, L. Mu, P.-C. Ma, Magnetic graphene foam for efficient adsorption of oil and organic solvents, Journal of Colloid and Interface Science 430 (2014) 337-344.

[7] A. Li, H.-X. Sun, D.-Z. Tan, W.-J. Fan, S.-H. Wen, X.-J. Qing, G.-X. Li, S.-Y. Li, W.-Q. Deng, Superhydrophobic conjugated microporous polymers for separation and adsorption, Energy \& Environmental Science 4(6) (2011) 2062-2065.

[8] E.U. Kulawardana, D.C. Neckers, Photoresponsive oil sorbers, Journal of Polymer Science Part A: Polymer Chemistry 48(1) (2010) 55-62.

[9] S. Liu, Q. Xu, S.S. Latthe, A.B. Gurav, R. Xing, Superhydrophobic/superoleophilic magnetic polyurethane sponge for oil/water separation, RSC Advances 5(84) (2015) 68293-68298.

[10] A. Sarkar, S. Mahapatra, Novel hydrophobic vaterite particles for oil removal and recovery, Journal of Materials Chemistry A 2(11) (2014) 3808-3818. 
[11] R. Li, C. Chen, J. Li, L. Xu, G. Xiao, D. Yan, A facile approach to superhydrophobic and superoleophilic graphene/polymer aerogels, Journal of Materials Chemistry A 2(9) (2014) 3057-3064.

[12] H. Bi, Z. Yin, X. Cao, X. Xie, C. Tan, X. Huang, B. Chen, F. Chen, Q. Yang, X. Bu, X. Lu, L. Sun, H. Zhang, Carbon Fiber Aerogel Made from Raw Cotton: A Novel, Efficient and Recyclable Sorbent for Oils and Organic Solvents, Advanced Materials 25(41) (2013) 5916-5921.

[13] M.-Q. Zhao, J.-Q. Huang, Q. Zhang, W.-L. Luo, F. Wei, Improvement of oil adsorption performance by a sponge-like natural vermiculite-carbon nanotube hybrid, Applied Clay Science 53(1) (2011) 1-7.

[14] X. Gui, H. Li, K. Wang, J. Wei, Y. Jia, Z. Li, L. Fan, A. Cao, H. Zhu, D. Wu, Recyclable carbon nanotube sponges for oil absorption, Acta Materialia 59(12) (2011) 4798-4804.

[15] I.A.W. Tan, A.L. Ahmad, B.H. Hameed, Adsorption of basic dye on high-surface-area activated carbon prepared from coconut husk: Equilibrium, kinetic and thermodynamic studies, Journal of Hazardous Materials 154(1-3) (2008) 337-346.

[16] M. Toyoda, M. Inagaki, Sorption and Recovery of Heavy Oils by Using Exfoliated Graphite, Spill Science \& Technology Bulletin 8(5-6) (2003) 467-474.

[17] S. Zhang, T. Shao, H.S. Kose, T. Karanfil, Adsorption of Aromatic Compounds by Carbonaceous Adsorbents: A Comparative Study on Granular Activated Carbon, Activated Carbon Fiber, and Carbon Nanotubes, Environmental Science \& Technology 44(16) (2010) 6377-6383.

[18] H.-W. Liang, Q.-F. Guan, L.-F. Chen, Z. Zhu, W.-J. Zhang, S.-H. Yu, Macroscopic-Scale Template Synthesis of Robust Carbonaceous Nanofiber Hydrogels and Aerogels and Their Applications, Angewandte Chemie 124(21) (2012) 5191-5195.

[19] X. Gui, J. Wei, K. Wang, A. Cao, H. Zhu, Y. Jia, Q. Shu, D. Wu, Carbon Nanotube Sponges, Advanced Materials 22(5) (2010) 617-621.

[20] H. Omidvarborna, A. Kumar, D.-S. Kim, Recent studies on soot modeling for diesel combustion, Renewable and Sustainable Energy Reviews 48 (2015) 635-647. 
[21] D.J. Campbell, M.J. Andrews, K.J. Stevenson, New Nanotech from an Ancient Material: Chemistry Demonstrations Involving Carbon-Based Soot, Journal of Chemical Education 89(10) (2012) 1280-1287.

[22] X. Deng, L. Mammen, H.-J. Butt, D. Vollmer, Candle Soot as a Template for a Transparent Robust Superamphiphobic Coating, Science 335(6064) (2012) 67-70.

[23] H. Liu, T. Ye, C. Mao, Fluorescent Carbon Nanoparticles Derived from Candle Soot, Angewandte Chemie International Edition 46(34) (2007) 6473-6475.

[24] H. Khojasteh, M. Salavati-Niasari, M.-P. Mazhari, M. Hamadanian, Correction: Preparation and characterization of $\mathrm{Fe}_{3} \mathrm{O}_{4} @ \mathrm{SiO}_{2} @ \mathrm{TiO}_{2} @ \mathrm{Pd}$ and $\mathrm{Fe}_{3} \mathrm{O}_{4} @ \mathrm{SiO}_{2} @ \mathrm{TiO}_{2} @ \mathrm{Pd}-\mathrm{Ag}$ nanocomposites and their utilization in enhanced degradation systems and rapid magnetic separation, RSC Advances 6(89) (2016) 86385-86385.

[25] D.D. Nguyen, N.-H. Tai, S.-B. Lee, W.-S. Kuo, Superhydrophobic and superoleophilic properties of graphene-based sponges fabricated using a facile dip coating method, Energy \& Environmental Science 5(7) (2012) 7908-7912.

[26] E.D. Dikio, Morphological Characterization of Soot from the Atmospheric Combustion of Kerosene, EJournal of Chemistry 8(3) (2011).

[27] H. Zhang, 1. Junting, J. Liu, S. Chen, H. Zhang, Z. Tian, Y. Cai, P. Wang, Y. Ye, C. Liang, Monodispersed carbon nanodots spontaneously separated from combustion soot with excitation-independent photoluminescence, RSC Advances 6(10) (2016) 8456-8460.

[28] J. Liu, X. Huang, Y. Li, K.M. Sulieman, X. He, F. Sun, Hierarchical nanostructures of cupric oxide on a copper substrate: controllable morphology and wettability, Journal of Materials Chemistry 16(45) (2006) 44274434.

[29] N. Chen, Q. Pan, Versatile Fabrication of Ultralight Magnetic Foams and Application for Oil-Water Separation, ACS Nano 7(8) (2013) 6875-6883.

[30] X. Zhou, Z. Zhang, X. Xu, X. Men, X. Zhu, Facile Fabrication of Superhydrophobic Sponge with Selective Absorption and Collection of Oil from Water, Industrial \& Engineering Chemistry Research 52(27) (2013) 94119416. 
[31] X. Zhou, Z. Zhang, X. Xu, F. Guo, X. Zhu, X. Men, B. Ge, Robust and Durable Superhydrophobic Cotton Fabrics for Oil/Water Separation, ACS Applied Materials \& Interfaces 5(15) (2013) 7208-7214.

[32] Q. Zhu, Y. Chu, Z. Wang, N. Chen, L. Lin, F. Liu, Q. Pan, Robust superhydrophobic polyurethane sponge as a highly reusable oil-absorption material, Journal of Materials Chemistry A 1(17) (2013) 5386-5393.

[33] L. Yu, G. Hao, S. Zhou, W. Jiang, Durable and modified foam for cleanup of oil contamination and separation of oil-water mixtures, RSC Advances 6(29) (2016) 24773-24779.

[34] H. Sun, A. Li, Z. Zhu, W. Liang, X. Zhao, P. La, W. Deng, Superhydrophobic Activated Carbon-Coated Sponges for Separation and Absorption, ChemSusChem 6(6) (2013) 1057-1062. 


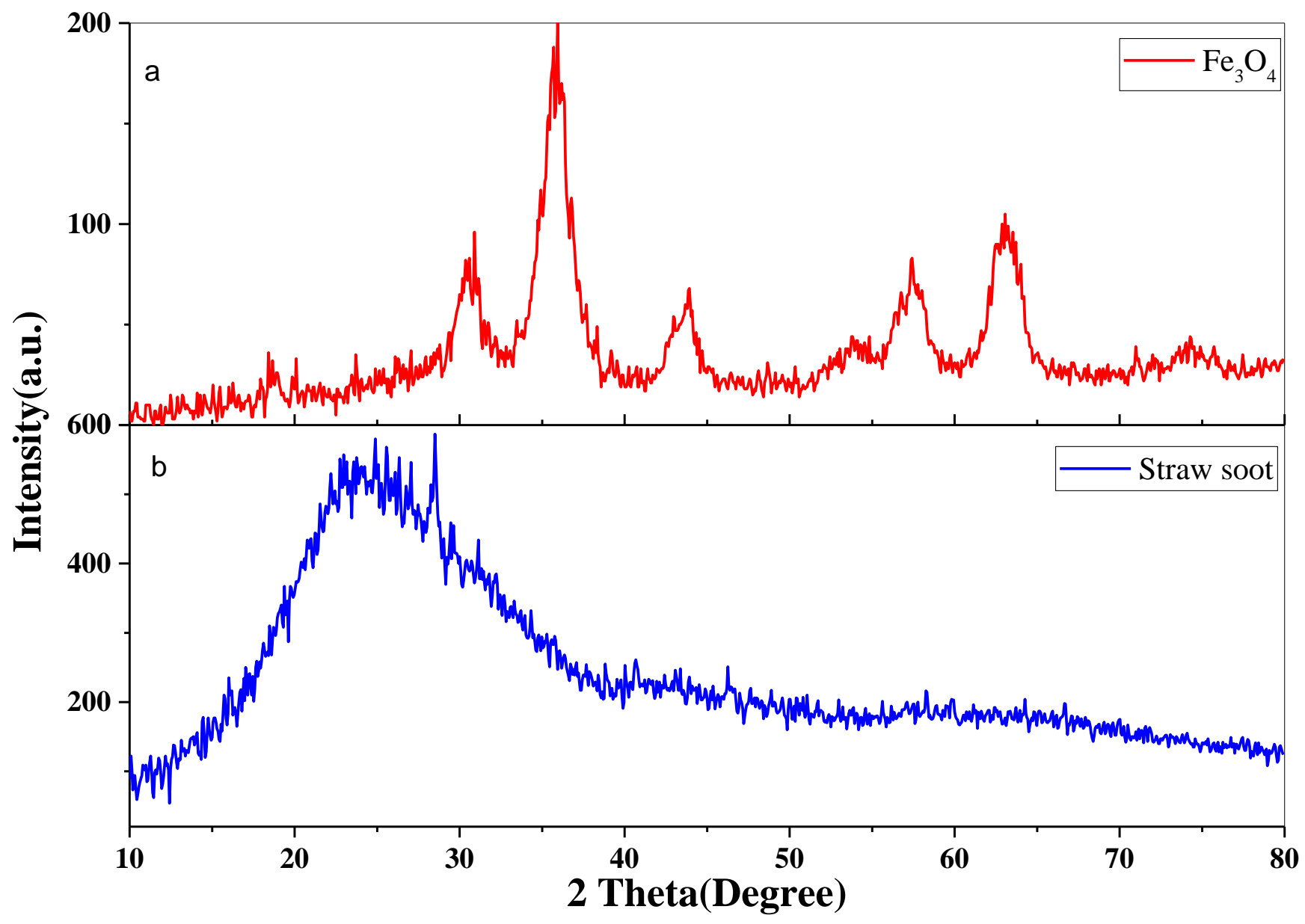

Fig. 1. 


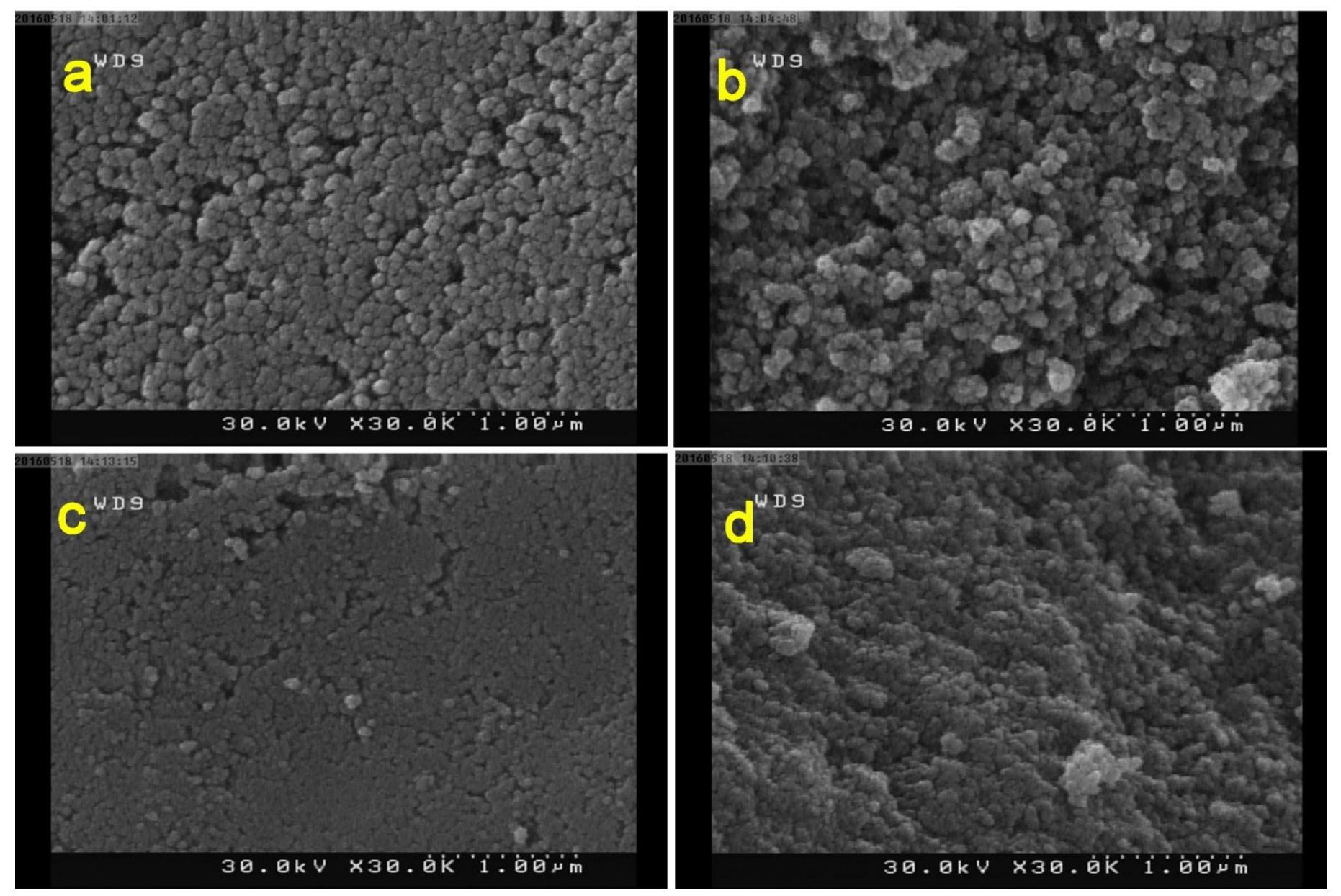

Fig. 2. 


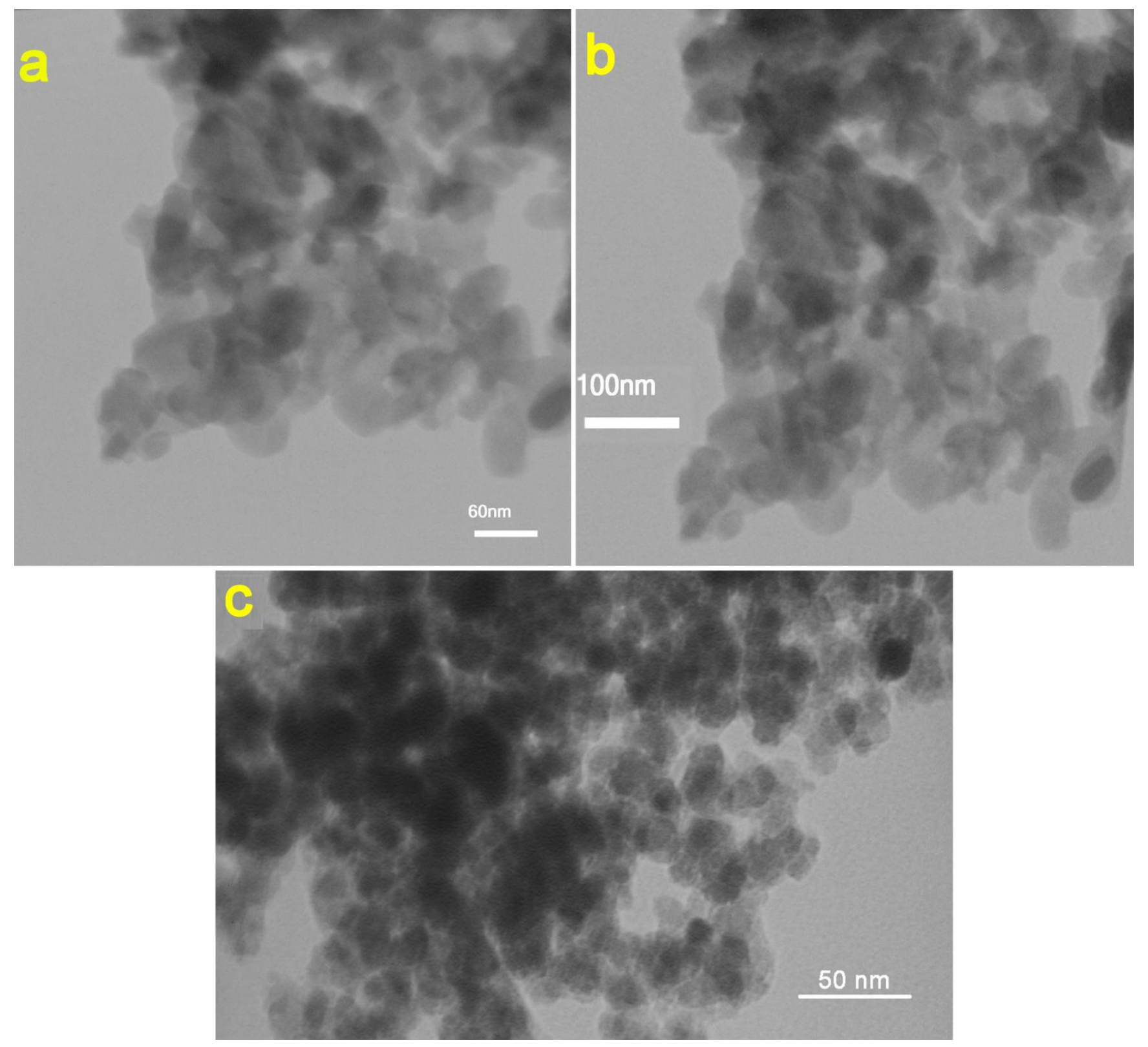

Fig. 3. 


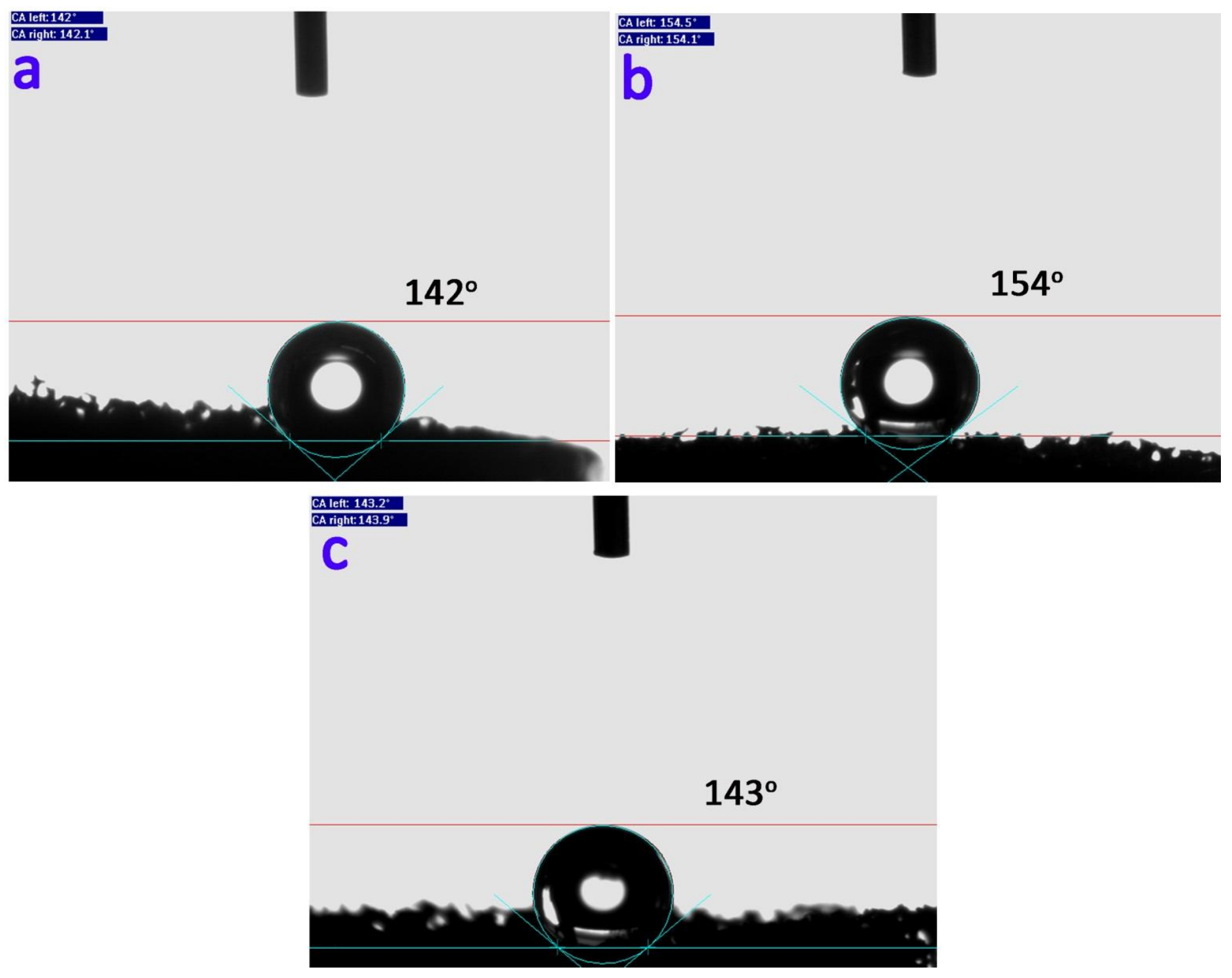

Fig. 4. 


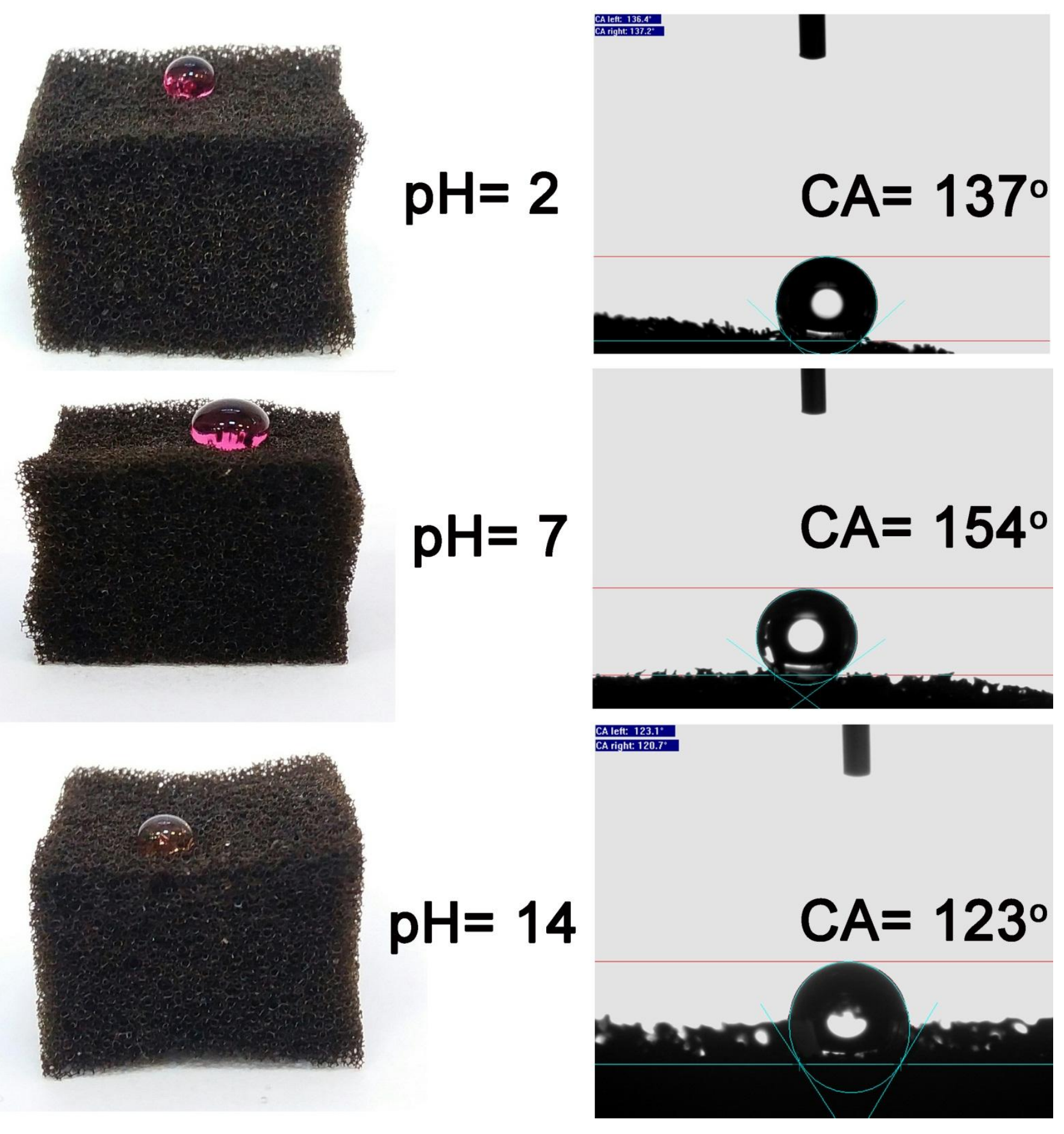

Fig. 5. 


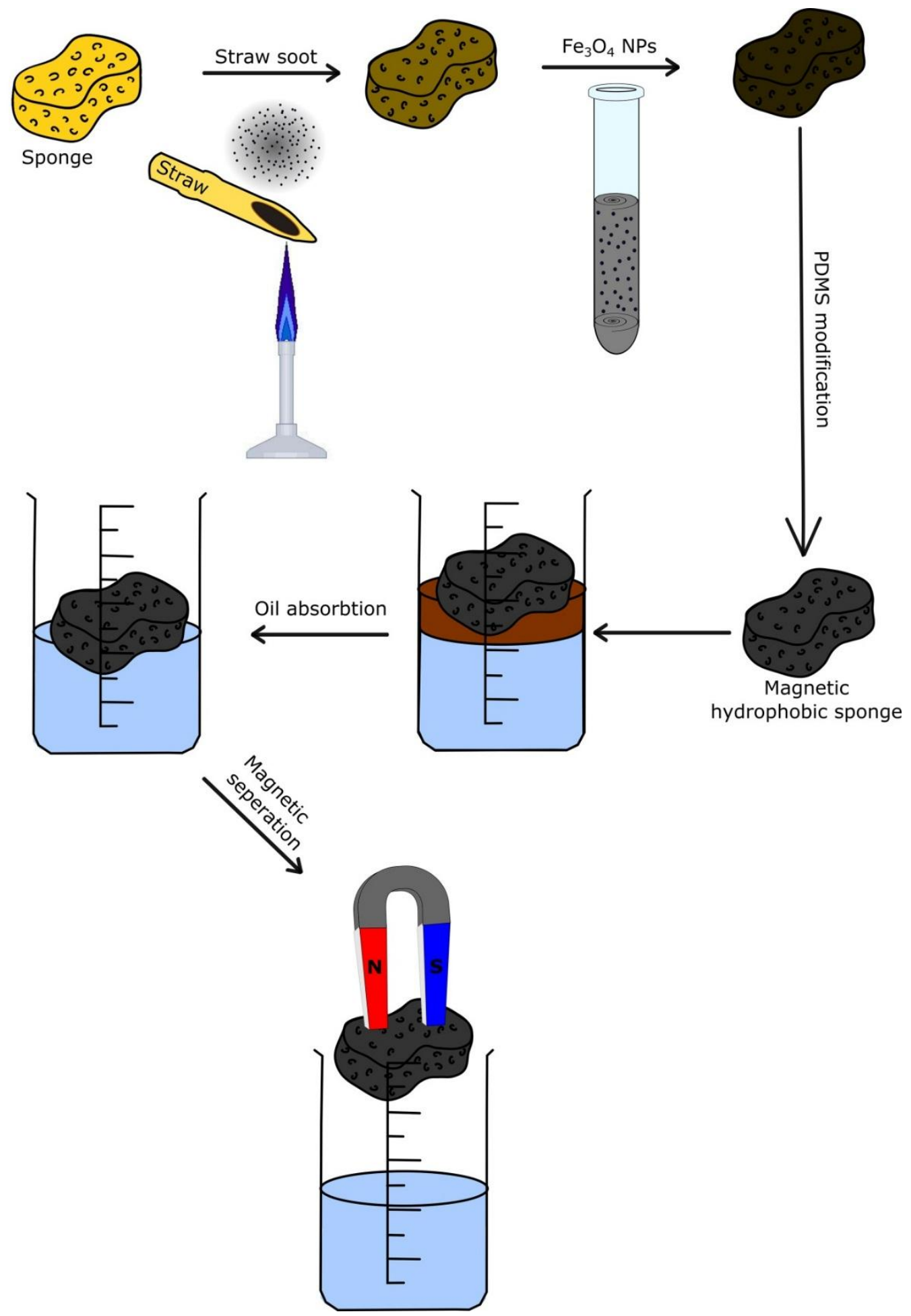

Fig. 6. 

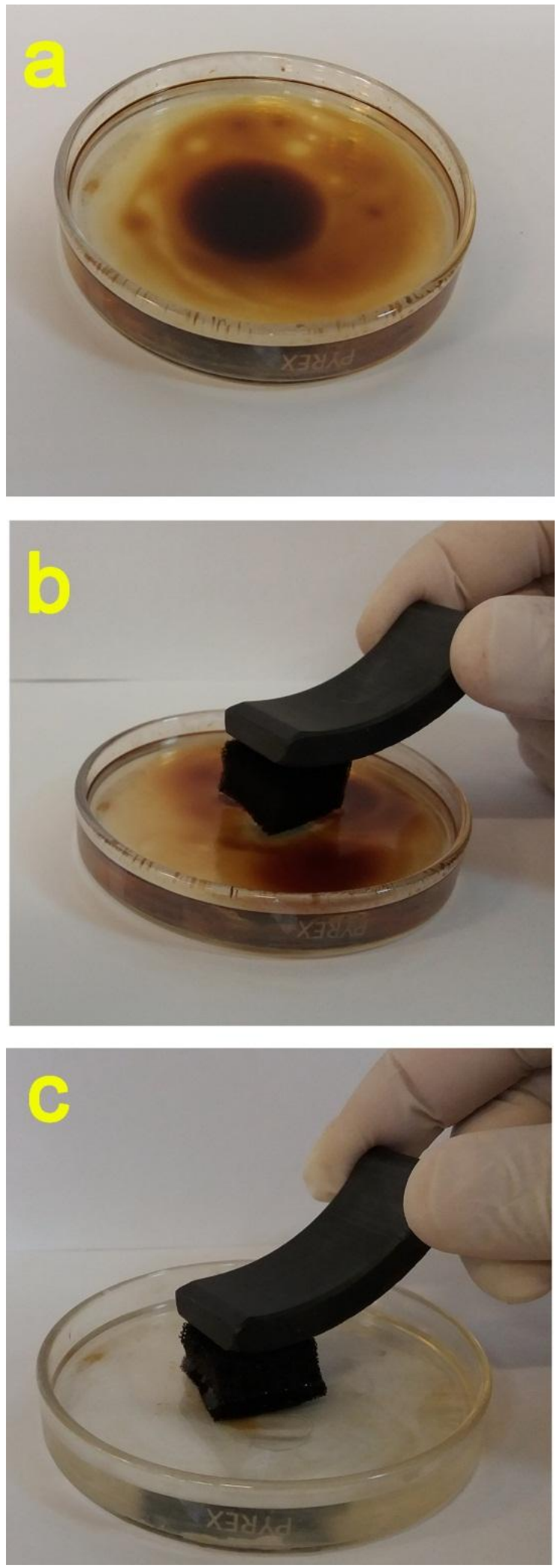

Fig. 7. 
Table 1.

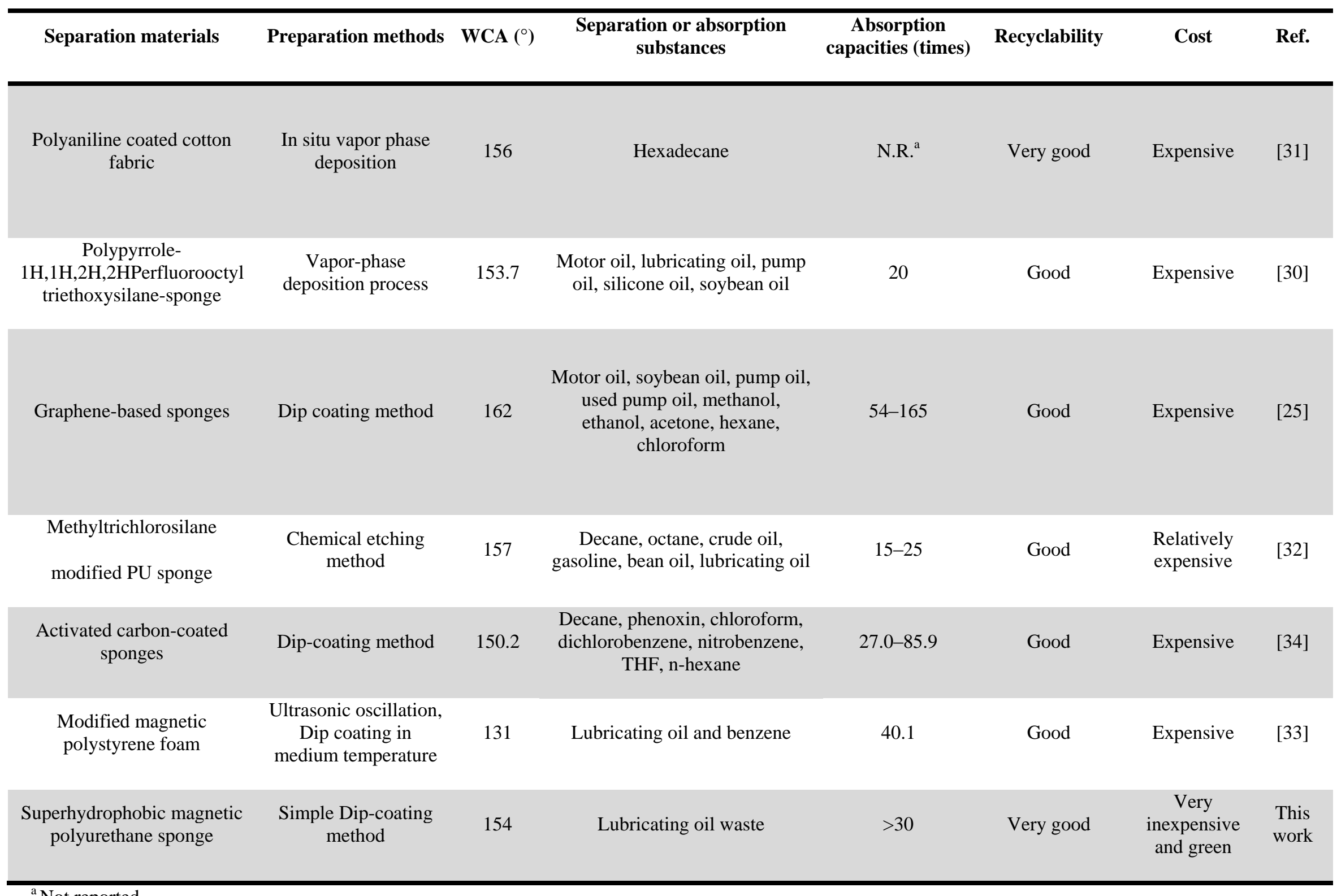

${ }^{\mathrm{a}}$ Not reported 

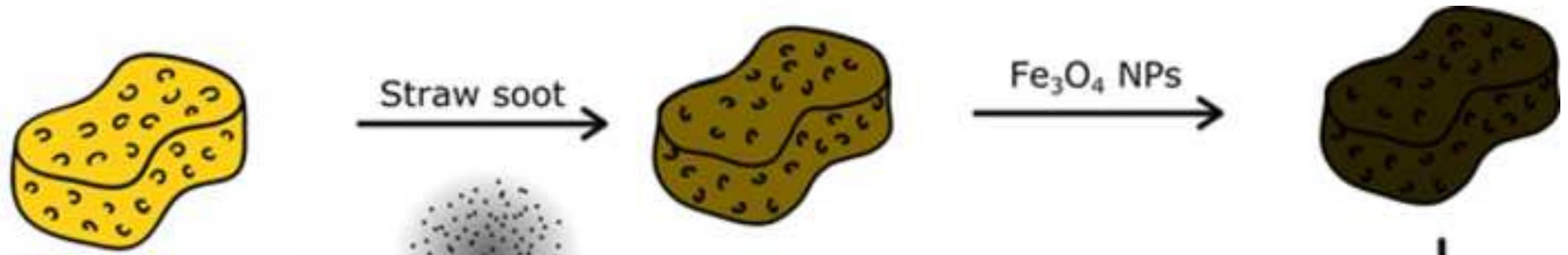

Sponge
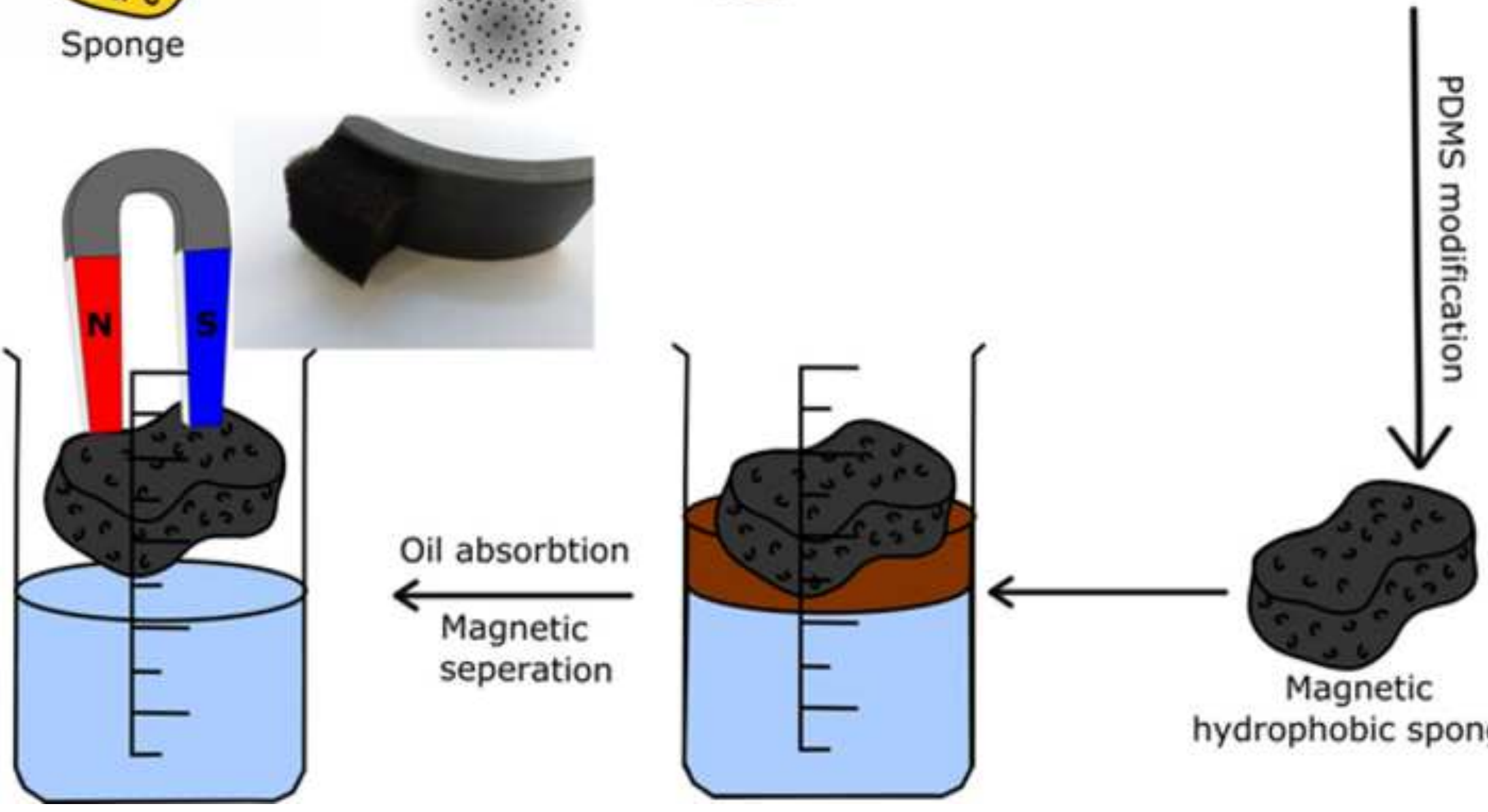

hydrophobic sponge 